


\section{Do you want to:}

- attract more participants?

- offer programs for people who haven't experienced your sport before?

- grow your membership?

- generate extra club revenue?

- have a vibrant and active club community?

- set your club up for the future?

- positively influence the health of Victorians?

- retain your members longer

\section{Why do sport differently?}

Nearly half of all Australians are not doing enough physical activity to benefit their health ${ }^{1}$. This contributes to the burden of obesity, chronic disease and mental illness in our community².

At the same time, trends in physical activity and sport participation are shifting. There is increased participation in social sporting activities and a decline in traditional, club-based sport (Hajkowicz et al. 2013).
'Doing sport differently' tackles these challenges by attracting, engaging and retaining less-active people in sports. While it takes time, doing sport differently can help sports attract larger and more diverse audiences, and provides opportunities for less-active people to enjoy the health benefits of sport.

\section{Who are 'less active' people?}

People who are less active are those who do not undertake at least 30 minutes of physical activity on at least 5 days of the week. People might be less active because they have dropped out of sport or decreased their activity levels as their life

circumstances changed, or they may never have been active enough. Less-active people may not like sport, or might have had bad experiences in the past.

Some people from particular target populations (e.g. from low socioeconomic areas, with disability, culturally and linguistically diverse, Aboriginal) may face particular barriers that prevent them from being active. People from these populations may be more likely than the general population to be less active. 


\section{How to do sport differently}

In recent years, VicHealth has been helping sport clubs keep pace with current trends by building more welcoming and flexible approaches to sport participation.

These included:

- new social sport participation products that make activities fun, social and local

- new introductory programs to connect someone to a sport for the first time

- new programs specifically designed for population groups that are under-represented in sport (e.g. people with disability or newly-arrived Victorians)
Doing sport differently requires rethinking where and how sport is delivered, and who delivers it. It may also require new systems, processes and ways of working. It needs patience and a commitment to a new direction.

The following pages outline six key principles for doing sport differently, along with tips and case studies to help clubs try something new.

\section{What is 'social sport'?}

Social sport is less structured than traditional sport. It has fewer rules and more flexibility. It can be designed and delivered by a sport governing organisation (e.g. state sporting association), sport club, local council or other individuals and groups.

Social sport places a greater emphasis on fun, social interaction and enjoyment than on performance, results and competition.

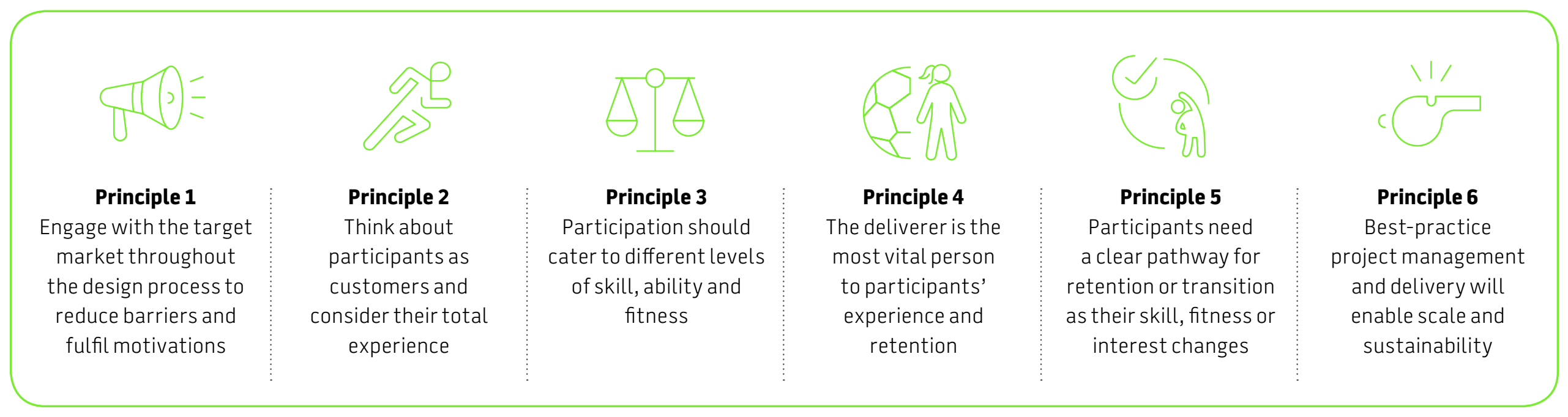




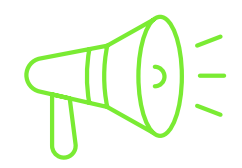

Potential participants could be new to sport, new to your sport, or they may not have participated in any sport for a while. They will have different needs, expectations, interests, questions and motivations, and their own unique previous experiences in sport (either positive or negative).

If you want to set up new participation opportunities at your club, one of the most important things you can do is talk to potential participants and learn as much as you can about them. Speaking with your target audience before you design an opportunity for them helps you understand them better, which will ensure that your approach is suitable.

\section{Engage with potential participants}

- Speak to potential participants and ask what they are looking for.

- Identify the people or organisations that have regular contact with potential participants and work with

them to help you to understand their barriers and needs.

- Think about gaps in your current programming:

- do you provide opportunities for different age groups and genders?

do you cater to various levels of ability (competitive and social)?

- can families participate together?

are there time slots that you are currently under-utilising?

- Find out what programs your state or national sporting associations have developed and think about whether they might suit potential participants in your community.

\section{CASE STUDIES}

Wyndham Track and Field club has made sure that everyone can join in track and field activities by keeping them fun and social, not serious.

Through a conscious effort to be more welcoming of new people and promotion with schools, the club has grown its membership, especially with women and multicultural communities. It is a vibrant and social place to be.

Swell Mamas, a new club founded in Inverloch Victoria, merges surfing and childcare. Swell Mamas helps women feel confident to get out on the water by letting them know it's something they can do, no matter what size or shape they are or what previous surfing experience they have had. Created by women for women, the club overcame many barriers to make it possible for participants to surf.

Saints Play has sought to understand the involvement and barriers for kids with autism when playing Auskick. The program has adapted the experience to be more inclusive by making a few small changes, which can be replicated in any Auskick centre. 


\section{Use innovative program design to overcome barriers}

Less-active Victorians who are currently sitting on the sidelines have specific barriers to participation. These barriers include:

- few options near where they live

- no options that suit them

- lack of confidence in their own abilities

- child or family care responsibilities

- lack of motivation

- injury

- low income level

- limited access to transport

- discrimination

These barriers can be more evident for groups that experience higher levels of disadvantage.
To address these barriers and better accommodate people's changing lifestyles, consider innovative ways of offering your sport to your community. Innovation doesn't necessarily mean creating something totally new. Innovative approaches can include:

- developing new or unique partnerships

- promoting your activities in a different way

- adapting an existing product to suit a wider audience

- improving a process to make it easier for people to take part.

Working with traditional and non-traditional partners (e.g. local councils, businesses, third party deliverers) can also increase opportunities for innovation and maximise resources and reach.

\section{Retain participants}

Talk to your participants regularly to find out what they are enjoying and what they would like to see changed.

If your aim is to retain existing members, you could:

- talk to people who have dropped out to find out why and ask how you could change things to keep them

- try to identify when people are leaving - is it because existing opportunities are no longer engaging or relevant?

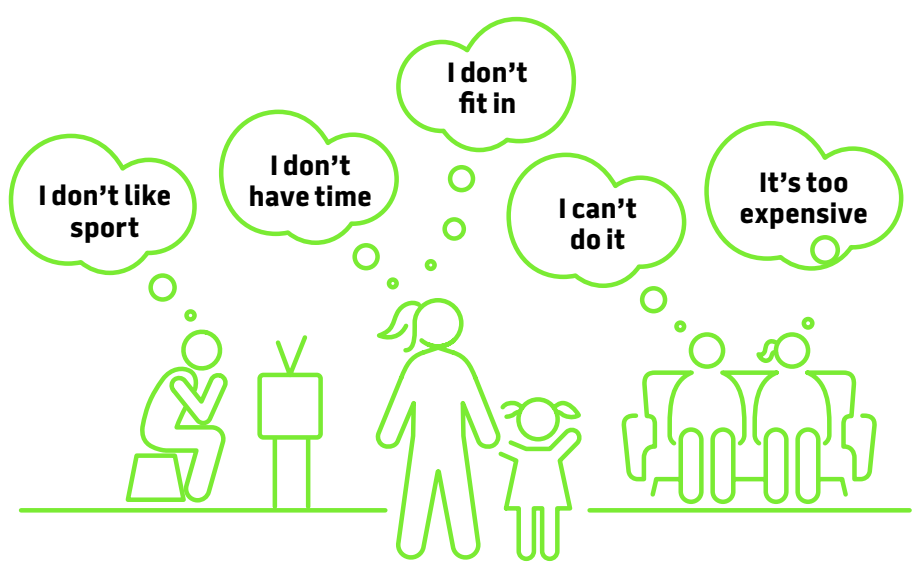

\section{Innovative program design}

\section{Flexible payment options \\ Relax the \\ dress code \\ Online videos \\ that show the \\ program}

\section{Modified rules and equipment}

\section{time slots}

Include socia activities or other incentives

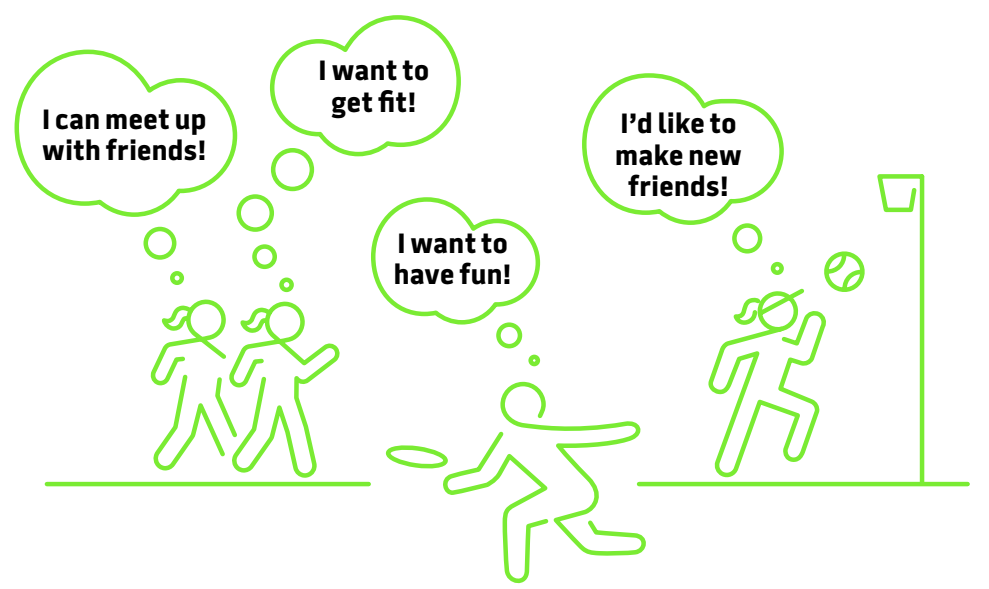




\section{PRINCIPLE 2: THINK ABOUT PARTICIPANTS AS CUSTOMERS AND CONSIDER THEIR TOTAL EXPERIENCE}

Try to see everything through the eyes of potential participants - how they will be feeling, what they want and what they need to make them feel more welcome and comfortable with your club?

A participant's experience is not limited to what they do in a session, but includes social and other aspects as well. Think of ways your club can improve participants' experiences at five key touchpoints.

\section{Marketing}

Joining a new club can be scary! The participant needs to see themselves fitting in at your club. Think about the images that you use to promote opportunities.

Local marketing strategies should reach beyond your current member channels. Don't just market through your existing social media pages and websites, as these generally only reach people who are already engaged with your club. Strategies that promote word of mouth (e.g. 'bring a friend' activities) as well as paid social media advertisements, local flyers and partnerships with organisations who engage with a potential audience (e.g. community groups, such as health organisations, religious groups and youth groups) are the most successful local strategies.

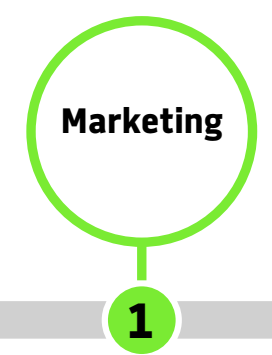

\section{Registration}

Less-active people often contemplate joining an activity for a while before they follow through. A simple and informative registration process reduces their fears and anxiety and makes sure they have a positive experience with your club from the first session.

Provide new participants with accurate information about your club and the opportunity you are offering before they get there - e.g. club address, clothing and equipment required, where to park, who to look for when they get there.

Mobile 'tap and go' payment systems and effective online registration processes are most successful.

\section{The welcome}

Choose someone to welcome new participants when they arrive, show them around and answer any questions, or assign a 'buddy' that can support the new
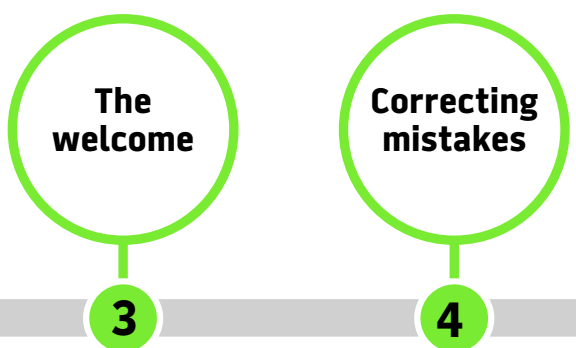

The invitation to return

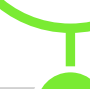

5

participant initally. This could be the program coach or deliverer, or a club official or volunteer.

\section{Correcting mistakes}

Making a mistake is a crucial moment in a participant's experience of a program. The deliverer must make sure that the environment is supportive. This includes the way in which fellow participants, as well as the deliverer, react to a mistake.

The participants' focus may not be on technical improvement and skill refinement, but enjoyment, friendships, health and fitness. In this case, it is less important to highlight technical errors.

\section{The invitation to return}

Having the deliverer invite participants back will reinforce personal connections and increase the likelihood of retention. You might also send a follow-up text or email. 
When an activity cannot be successfully completed, or is not challenging enough, participants are more likely to disengage with a program.

When activities are flexible and can be modified and adapted for all members of the group, participants are more involved and can increase their level of confidence and ability over time.

Think about how your activities might be modified to suit participants' needs. This could be done through:

- using different equipment

- having different movements to increase or decrease the challenge

- splitting participants into groups according to skill, ability and fitness levels

- changing the rules, playing area, duration of games or scoring to suit everyone's skill level and ability.

It is also important to consider injury prevention, particularly when participants are new to your sport or haven't been physically active for a while.

\section{CASE STUDY}

In Golf Australia's Swing Fit program, golf and fitness activities were designed to be done in pairs, so that beginners and re-entry participants could be matched. Alternatively, if a re-entry and beginner were paired, the facilitator could motivate the re-entry participant to be a role model or mentor for the beginner. Managed well, this approach can motivate and challenge all participants and build positive relationships.

I appreciate riding with a group of people in my own age bracket - I don't feel pressured to keep up.

Participant in a Life Cycle 55+ cycling program

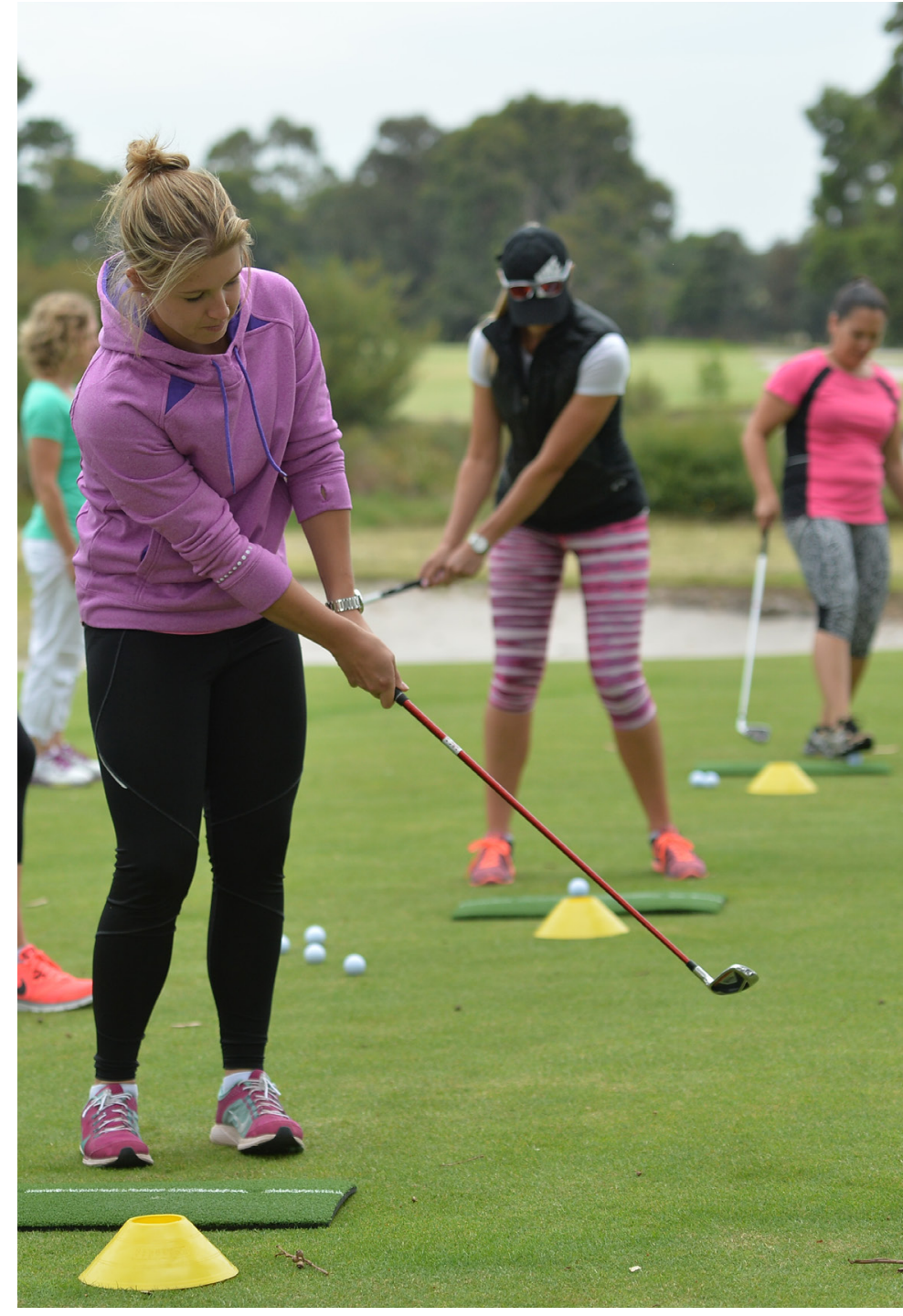




\section{PRINCIPLE 4: THE DELIVERER IS THE MOST VITAL PERSON TO PARTICIPANTS' EXPERIENCE AND RETENTION}

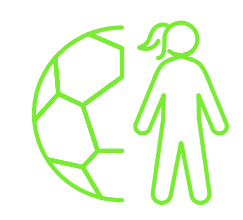

The deliverer - the person facilitating the activity - is responsible for welcoming, engaging and encouraging participants.

Deliverers will be most effective if they:

- are empathetic, encouraging, and relatable

- take a high level of interest in and care for participants

- set the culture and create a fun environment

- provide clear instructions about the rules and activities

- adapt and modify activities to suit the skill, ability, fitness level and engagement of participants

- highlight and appropriately reward participants' achievements, however small

- facilitate ongoing physical activity opportunities for the participant.

I liked that it was not an intimidating experience. It was lots of fun and the deliverers were very helpful and encouraging. It is a great program to introduce people to golf or for people who have played golf in the past.

Participant in a Swing Fit golf program
When you are recruiting and training deliverers, focus on their ability to interact with participants rather than just their technical coaching ability.

Whether they are paid staff or volunteers, deliverers should be adequately trained to deliver programs to less-active people and understand the aims of the program as well as the activities to be delivered. Often your State Sporting Association, Regional Sports Assembly or local council can help with training.

[The deliverers] are very encouraging with my son. They always verbally say 'great pass', 'awesome effort', 'nice shot', to all the kids playing. They clearly enjoy working with the kids as they are always enthusiastic and smiling.

Parent of a participant in a wheelchair basketball program




To retain participants in your club, consider 'What's next' for them, particularly those who have taken part in short-term opportunities like a 'Come and try' day or a 4-6 week introductory program.
What participants want to do next will vary. Some will continue in the same program. Some will increase their skill and fitness through the program and seek more challenging opportunities, which may include transition to more traditional formats of the sport. For others, their interest and skill may decrease (e.g. as they age, or after having a baby), meaning that a different social offering will be more attractive.
Some participants enjoy variety in their activities, and others prefer to stick with the sport they have come to know (at the appropriate level).

Remember that successful transitions are often dependent on the quality and knowledge of the deliverer and how well they encourage continuation and link to new opportunities.

\section{PRINCIPLE 6: BEST-PRACTICE PROJECT MANAGEMENT AND DELIVERY WILL ENABLE SCALE AND SUSTAINABILITY}

If your program is a success, you may want to run it again. For the program to become an ongoing part of your club's offerings, it needs to be financially viable and have someone who can drive it. Consider early who will plan, promote and deliver the program the next time.

Costs might include the deliverer, facility hire,

equipment, uniforms and marketing. Sometimes these costs can be large, particularly if specialist equipment is needed (e.g. wheelchairs).
Understand what it costs to run the program and how you can cover those costs in an ongoing way. Think about:

- How much will you charge participants?

- Can you gain any revenue from other sources (e.g. government grants, incentives from state sporting associations, sponsors)?

- Can you subsidise fees for people who are less able to pay by using existing revenue?

You may be able to apply for a VicHealth Active Club Grant or another grant to support your activity.

\section{CASE STUDY}

Basketball Victoria employed an effective strategy to reduce program costs for its wheelchair basketball program. The lack of wheelchairs was a key barrier to the program's sustainability and growth. Basketball Victoria first helped clubs to share wheelchairs, and then assisted them to build up their own bank of wheelchairs through channels such as government grants, corporate sponsorships and gifts. 


\section{Tell us about your success}

While it takes time, doing sport differently can help your club grow and engage with larger and more diverse audiences, and provide opportunities for less-active people to enjoy the health benefits of sport.

Don't forget to keep us in the loop. We would love to hear what you've achieved! Tag@VicHealth on Facebook, Instagram and Twitter,

or email us at publications@vichealth.vic.gov.au

\section{Acknowledgement}

VicHealth acknowledges the Centre for Sport and Social Impact at La Trobe

\section{Vichealth}

Victorian Health Promotion Foundation PO Box 154 Carlton South

Victoria 3053 Australia

$T+61396671333 F+61396671375$

vichealth@vichealth.vic.gov.au

vichealth.vic.gov.au

twitter.com/vichealth

facebook.com/vichealth

VicHealth acknowledges the support of the Victorian Government.

(c) VicHealth 2019

September 2019 P-PA-787 